\title{
Control and Anticipation of Social Interruptions: Reduced Stress and Improved Task Performance ${ }^{1}$
}

\author{
AndReW M. CARTON ${ }^{2}$ \\ Fuqua School of Business \\ Duke University
}

\author{
JOHN R. AIELLO \\ Rutgers University
}

\begin{abstract}
Social interruptions are frequent occurrences that often have distressing consequences for employees, yet little research has gauged their effect on individuals. Participants were exposed to 2 social interruptions as they engaged in a computer task with an accepted performance goal. Participants who were able to anticipate social interruptions performed significantly better than did those who could not anticipate them. Participants who had the opportunity to prevent interruptions reported significantly less stress than those who did not have this opportunity. This reduction in stress resulted even when participants did not take advantage of this opportunity. Implications for job performance and job satisfaction are discussed. Organizational strategies for how leaders can help employees manage social interruptions are suggested.
\end{abstract}

In recent years, as networking within organizations has become more complex, interactive, and interdependent, the social interruption has established itself as a widespread problem (Perlow, 1999). Although managers frequently cite social interruptions as among the most burdensome of workplace realities, research on interruptions has been predominantly limited to the domains of communications, technology, computing, aviation, and cognition, with little investigation by social psychologists or scholars in organizational behavior (for a review, see McFarlane and Latorella, 2002). Specifically, little academic research has investigated the best methods for curtailing the negative consequences of social interruptions. We propose that two basic functions of social perception, control and anticipation, will allow individuals to cope better with the debilitating consequences of these disruptions to work flow and concentration.

${ }^{1}$ The authors thank Jason Glushakow for his help with statistical analyses; Richard Larrick and Sim Sitkin for their insights on earlier versions of the paper; and Jaclyn Zires for her detailed comments on a previous draft.

${ }^{2}$ Correspondence concerning this article should be addressed to Andrew M. Carton, Fuqua School of Business, Duke University, 1 Towerview Drive, Box 90120, Durham, NC 27708. E-mail: andrew.carton@duke.edu 
Recently, there has been more agreement among researchers regarding what constitutes an interruption; however, there is often a lack of conceptual and scientific clarity attributed to their studies (Moray, 1993). For the purpose of this study, an interruption can be defined as any disruptive event that impedes progress toward accomplishing organizational tasks (Grove, 1983; Jett \& George, 2003). Social interruptions are those that are initiated by human actors.

Generally, social interruptions are viewed as a necessary burden in modern organizations because they play an essential role in organizational continuity. For example, spontaneous communication (Dabbish \& Kraut, 2004), taking place both vertically and horizontally in organizations, may result in benefits such as the transfer of knowledge and, in turn, the establishment of new work routines. Yet, despite their necessity, there are strong indications that, as social interruptions have increased in frequency and severity, their effects have become damaging to employee well-being and performance.

Employees often feel powerless to maintain an environment in which they can sustain total immersion in a task while budgeting enough time to get tasks accomplished (Perlow, 1999). Newsletter and newspaper articles documenting the negative stigma of social interruptions carry headlines such as "Little Disruptions Can Steal Away a Whole Day" (McCorry, 2001), and "Manage Time Effectively by Putting an End to Interruptions" (Jacobs, 2004). When the widespread negative perception of social interruptions is coupled with the accelerated use of novel communications devices (e.g., e-mail, instant messaging, text messaging), it becomes clear that employees are in a vulnerable position. Today's managers thus face a dilemma because they must help employees manage the most distressing consequences of social interruptions while maintaining the benefits of interruptions for knowledge dissemination and work routines.

\section{Managing Social Interruptions}

An investigation into the potential for managing the consequences of social interruptions must address why they are sustained. Research has suggested that the interrupter gains more from the interruption and incurs less cost than does the interrupted (Kraut \& Attewell, 1997; O'Conaill \& Frohlich, 1995). This lopsided cost-benefit scenario fuels the ubiquity of social interruptions because it is often in an interrupter's best interests to interrupt another worker, and there is little incentive for him or her to discontinue this behavior. 
Thus, interruption-management strategies aimed at discouraging potential interrupters are unlikely to be successful. For example, Fogarty, Lai, and Christensen (2004) suggested that individuals with access to automatically encoded information about worker availability tend to continue with a regular level of interrupting, regardless of whether coworkers are shown to be available or occupied in other tasks or conversation. Instead of using these cues for their intended purpose - as a gauge of coworker availability and as a signal not to interrupt if workers were occupied - they were used mostly as an indicator of presence. Given the imbalance between the costs incurred and benefits gained for the interrupters and the interrupted, respectively, we argue that the best alternative for managing the effects of interruptions is to focus on the party that reaps fewer rewards and incurs greater costs: the interrupted.

Because of their disruptive nature and potential to cause distress, we conceptualize social interruptions as aversive stimuli from the point of view of those who are interrupted. An aversive stimulus is one to which an individual or organism attempts to minimize exposure (Catania, 1968). In accordance with the dominant factors that have emerged in research on coping strategies amid aversive stimuli (Glass \& Singer, 1972), we propose that the cognitive mechanisms of anticipation and perceived control will systematically impact task performance and stress when applied to an environment that promotes social interruptions.

\section{Anticipation, Perceived Control, and Performance}

An extensive amount of research, particularly in communications and computing, has been generated on the performance-related deficits of nonsocial interruptions. Interruptions may cause increases in processing time and error rates (Cellier \& Eyrolle, 1992), memory loss and less accurate recall (Oulasvirta \& Saariluoma, 2004), deleterious effects on decision-making processes (Speier, Vessey, \& Valacich, 1999), and breaks in concentration (Altmann \& Trafton, 2004). All of these consequences may lead to demonstrable defects in performance as a result of the limits of attention while working on a task. Moreover, impairment to performance is extremely likely when individuals are forced to address interruptions immediately (McFarlane, 1999).

Resumption lag, defined as the period of time an individual needs to recover concentration and resume task performance at pre-interruption levels (Altmann \& Trafton, 2004; Hodgetts \& Jones, 2006), may be responsible for much of the impairment in performance. Evidence has suggested that the ability to anticipate and prepare for interruptions will reduce 
resumption lag and increase coping strategies. Cues that were available prior to interruptions allowed interrupted parties to prepare for them, thereby reducing resumption lag and improving performance (Altmann \& Trafton, 2004; Nagata \& van Oostendorp, 2003). Monk (2004) revealed that resumption lag and the resulting detriment to performance may be reduced when interruptions are more frequent (as long as duration remains constant) because actors engage in stronger, more aggressive coping and goalmaintenance strategies. ${ }^{3}$

The benefits of anticipation are likely to move beyond the ability to grapple successfully with resumption lag. In a series of experiments by Glass and Singer (1972), participants who were given information that allowed them to anticipate aversive stimuli (i.e., noise bursts) performed better and reported reduced stress. It was suggested that this may have been a consequence of increased tolerance for frustration in conditions in which noise bursts were signaled and, therefore, could be anticipated. Following from this evidence, an increased tolerance for aversive distracters (e.g., interruptions) is likely to benefit task performers. Moreover, the ability to focus and block out distracters is considered a critical mechanism for improving goal attainment (Locke \& Latham, 1990). In sum, the evidence presented here suggests that the ability to anticipate interruptions will lead to stronger task performance, thus we propose the following:

Hypothesis 1 . Greater ability to anticipate social interruptions will result in improved task performance.

Much influential research has suggested that a higher degree of control will also lead to better performance (Aiello \& Svec, 1993; Glass \& Singer, 1972). Other findings, however, have questioned this possibility. For example, Gillie and Broadbent (1989) suggested that disruption of performance may occur even when aspects of the interruption can be controlled.

Hypothesis 2. Greater perceived ability to control the environment will result in improved task performance.

\footnotetext{
${ }^{3}$ It is important to note that not all interruptions are created equal. The disruptive effect of interruptions depends on factors such as the similarity between the content of the interruption and the task being interrupted (Cellier \& Eyrolle, 1992; Gillie \& Broadbent, 1989), and the complexity of the interruption or the interrupted task (Gillie \& Broadbent, 1989; Speier et al., 1999).
} 


\section{Perceived Control and Stress}

Perceived control has been shown to have a profound effect on worker stress (Spector, 1986) and well-being more generally (Langer, 1983). In Karasek's (1979) model of job strain, high job demands paired with perceived low levels of control result in the most stressful work conditions. In the series of studies by Glass and Singer (1972), individuals who were given the ability to prevent an environmental stimulus from occurring reported significantly less stress than did those who did not have this ability. Most remarkably, these results held true even though participants did not actually take advantage of the opportunity to prevent the noise bursts. All individuals were exposed to identical circumstances, yet those with the perception that they could alter their circumstances, if they chose to do so, experienced less stress. The ability to control the environment was, on its own, a psychological tool with sufficient power to reduce stress. This power contrasted with a feeling of helplessness that those without control may have experienced.

Subsequent research has reinforced the power of perceived control as a psychological device that can alleviate stress and improve task performance (Aiello \& Svec, 1993). Synthesizing knowledge from models related to perceived control (e.g., job strain, work flexibility, environmental stressors), the benefits of perceived control, including reduced stress, are likely to be enhanced when an environmental stimulus is particularly aversive (e.g., noise bursts) and when one is looking to protect something that is highly valued (e.g., autonomy; Baltes, Briggs, Huff, Wright, \& Neuman, 1999; Glass \& Singer, 1972; Karasek, 1979). Social interruptions are often stressful stimuli because they impede valued resources, such as work time, concentration, and a sense of autonomy as workers scramble to fulfill their responsibilities (Corragio, 1990; Kirmeyer, 1988; Speier et al., 1999). The ability to prevent social interruptions, therefore, is likely to reduce stress.

Hypothesis 3. Greater perceived ability to control social interruptions will result in reduced stress.

There will be no prediction concerning the level of stress that individuals who can anticipate interruptions will experience versus those who will not have this ability, as findings in the literature relating the anticipation of aversive stimuli to stress are equivocal (Glass \& Singer, 1972; Yamamotová et al., 2000). We know of no research that has investigated an interaction between the opportunity to anticipate and the ability to control; however, we have decided to structure the experiment to investigate the potential for this effect because of the important implications of such a finding. 


\section{Method}

\section{Participants}

Study participants were 74 undergraduates (49 male, 25 female) who participated in the study to fulfill course requirements. The data for 4 participants were not included in the analyses because of malfunctioning hardware and errors in the execution of interruptions. Of the 70 participants whose data were used in analyses, 47 were male and 23 were female.

\section{Design}

The experiment used a $2 \times 2$ factorial design. The conditions - defined by the participant's ability to control or anticipate social interruptions during the main task-were control/anticipation, control/no anticipation, no control/anticipation, and no control/no anticipation.

\section{Procedure}

Main task. The rationale given for the study was to examine how individuals perform a task under time pressure. The participants were asked to sit at a computer to complete a 2-min typing task to assess baseline typing speed rates, which were recorded. The participants' main task was to complete an administrative procedure within a fixed period of time in order to achieve an assigned performance goal. Research has shown that, because time and flow of concentration are essential for completing projects, the existence of deadlines often engenders the perception of a dearth of time for the completion of designated tasks (Perlow, 1999). Thus, effects on performance and stress may be enhanced when a time-sensitive schedule is disrupted.

Participants had to scan through an article, find all the words that began with the letter "a," and type them into cells of a spreadsheet in the order in which they appeared in the article. After the participants finished transferring words that begin with the letter "a," they were asked to follow the same instructions for words beginning with the letter "b." Once they had completed transferring all of the " $b$ " words in the article, they continued to words beginning with the letter "c," and so on. Participants were asked to accept a goal of transferring 200 words in the 12-min period allotted for completion of the task. All participants accepted this target as their performance goal. Before participants were asked to begin the main trial, they were given additional information, depending on the condition to which they were exposed. 
Control/anticipation. For the control/anticipation condition, the participants were informed that another supervisor may be stopping by to perform some logistical functions for the experiment. Participants were also told that, if desired, they could use a "Do Not Disturb" sign to prevent anyone from coming by during the main trial, or they could close the door, which would be left ajar during the experiment. They were told that closing the door would provide the same effect as using the "Do Not Disturb" sign. They were told that they could either hang the sign up on the door of the room in which they were performing the task, or they could slide the sign under the door.

Control/no anticipation. For the control/no anticipation condition, the participants were told that they could use a "Do Not Disturb" sign to prevent anyone from coming by during the main trial, or they could close the door, which would be just as effective as using the "Do Not Disturb" sign. They were told that they could either hang the sign up on the door of the room in which they were performing the task, or they could slide the sign under the door.

Participants were not given any information that would allow them to anticipate that someone would stop by during the main task. To make the interruptions unpredictable for participants, supervisors used the wording "in the event that someone stops by the room ...". Interrupters were trained through body language, delivery, and voice inflection to make the possibility of an interruption seem unlikely and not salient to participants.

No controllanticipation. For the no control/anticipation condition, the participants were informed that another supervisor may be stopping by to perform some logistical functions for the experiment. However, they were not given any ability to control whether someone would stop by.

No control/no anticipation. Finally, for the no control/no anticipation condition, the participants were not given any additional information. They were not given any ability to control whether someone would stop by, nor were they given any information that would allow them to anticipate that someone would stop by during the main task.

Interruptions. All of the participants in each condition were interrupted twice. The specific form of social interruption implemented was an intrusion, which, according to Jett and George (2003), is an encounter "initiated by another person that interrupts the flow and continuity of an individual's work and brings that work to a temporary halt" (p. 495). There are several manifestations of the social interruption, yet an intrusion is perceived to be the most abrupt and obtrusive form. Participants were told they had $12 \mathrm{~min}$ to complete the administrative task. In reality, they had $11 \mathrm{~min}$ to complete the task: 1 min of task time was lost to the two 30 -s social interruptions.

Supervisors were thoroughly trained in the execution of the interruptions in order to ensure that the interruptions did not exceed the range of 29 to $31 \mathrm{~s}$. All interruptions were timed by another experimenter to ensure that they 
were executed within these time boundaries. To ensure a realistically disruptive effect, the interruptions were constructed so as to appear relevant and necessary for the existence of the study. The first interruption, occurring after 4 min had expired in the main trial, consisted of a second supervisor entering the room and asking the participants to stop working immediately. The supervisor then told the participants that they needed to obtain two more pieces of personal information right away or they would not be given credit for the experiment in a timely manner. They were then told that they could resume the task. The second interruption occurred after 8-1/2 min expired in the main trial. It consisted of a third supervisor entering the room and asking the participant to stop working on the main task. The supervisor then ejected a floppy disk from the computer, explaining to the participant that the disk contained old data and needed to be removed.

\section{Dependent Measures}

A five-item stress scale adopted from Aiello and Kolb (1995) was used to assess stress during the experimental session (see the Appendix for the complete scale). The measure of performance was the number of words accurately transferred from the article to the spreadsheet during the allotted time.

\section{Results}

\section{Manipulation Checks}

As a check on the manipulation of the independent variable intended to measure the degree to which participants could anticipate someone interrupting them, participants were asked if the lead supervisor had given them information before the session began that would allow them to anticipate that someone was going to interrupt them, $F(1,68)=4.92, p<.05$ (anticipation condition, $M=2.92$; no anticipation condition, $M=4.13$ ). Lower values denote a stronger sense of being able to anticipate the interruptions. As a check on the manipulation of perceived control, participants were asked whether they had full and complete ability to prevent the interruptions from happening. Participants' perception of control was congruent with conditions in which participants could prevent interruptions, $F(1,67)=117.33$, $p<.001 .^{4}$ None of the participants in these two conditions followed through

\footnotetext{
${ }^{4}$ There was 1 participant in the perceived control condition who did not answer this question.
} 
to prevent the interruptions by closing the door or by using the "Do Not Disturb" sign.

\section{Performance}

In support of Hypothesis 1, a between-factor ANOVA shows that participants who were able to anticipate interruptions transferred more words from the article to the spreadsheet $(M=144.11)$ than did those who were not provided with the information that people may be stopping by during the main task $(M=125.84), F(1,66)=4.14, p<.05, \eta_{p}{ }^{2}=.059$. This result provides support for the prediction that individuals who have the opportunity to anticipate interruptions perform better than those who do not have this opportunity. Hypothesis 2, which predicted that greater perceived control would improve performance, was not supported.

\section{Stress}

The five-item stress scale adopted from Aiello and Kolb (1995) had very strong inter-item reliability (Cronbach's $\alpha=.895$ ). In support of Hypothesis 3 , a univariate ANOVA using this scale as the dependent variable demonstrated that participants experienced significantly less stress during the overall session if they had the ability to prevent the interruptions from happening $(M=2.58)$, as compared to if they $\operatorname{did}$ not $(M=3.05), F(1$, 66) $=4.44, p<.05, \eta_{p}{ }^{2}=.063$.

\section{Discussion}

There are two major contributions from the present research. First, the opportunity to anticipate social interruptions leads to better task performance. We argue that individuals with knowledge that they may be exposed to aversive stimuli (e.g., interruptions) have the ability to use preventive coping tactics to minimize disruption and frustration when interruptions occur (Altmann \& Trafton, 2004; Glass \& Singer, 1972). Knowing beforehand that an interruption could occur might also allow for the opportunity to make the mental preparations necessary to cope with resumption lag, an outcome of interruptions related to the impairment of worker concentration (Hodgetts \& Jones, 2006). In the case of reduced resumption lag, time is saved and individuals have better ability to "re-attain" concentration. 
The second contribution is our finding that the opportunity to control social interruptions leads to reduced stress. Individuals need not actually prevent interruptions from happening in order to be benefited. Instead, simply the belief that they could prevent them, if they wanted, provided enough psychological leverage to reduce stress. Indeed, no participant actually used the "Do Not Disturb" sign or closed the door to prevent interruptions. It was the mere knowledge that they had the opportunity for this control that was sufficient to reduce stress.

This result reinforces results from studies in other domains of psychology (Aiello \& Svec, 1993; Glass \& Singer, 1972), and may be of the most practical import for managers. The implication is that managers may be able to "have their cake and eat it, too." First, employees may experience increased job satisfaction as a result of a reduction in stress (Brewer \& McMahon-Landers, 2003). Second, by not severely curbing social interruptions, many of their benefits for organizational operations are maintained (Dabbish \& Kraut, 2004).

Contrary to our expectations, participants who had the opportunity to control social interruptions did not perform better than those who did not have this opportunity. One possible explanation is that, unlike anticipation, perceived control does not allow individuals to cope with resumption lag. Even if the perception of control reduced stress, the interruptions still occurred in all cases, thus impairing the ability to concentrate.

Another finding of note is that participants who had the ability to anticipate interruptions reported the same degree of stress as those who could not anticipate interruptions. Correspondence between the ability to anticipate an interruption and stress levels was very difficult to predict because of conflicting evidence. Some research has posited that the anticipation of aversive stimuli may allow individuals to employ coping mechanisms that help them to reduce stress (Glass \& Singer, 1972), while other research has suggested that simply the anticipation of stressful events can be a powerful stressor on its own (Yamamotová et al., 2000). These determinants may have offset one another to neutralize the impact on stress resulting from the ability to anticipate social interruptions.

\section{Practical Steps for Managers}

In combination, the results of this study strongly suggest that individuals who have a degree of power over social interruptions - whether it was the awareness that they were going to occur, or the ability to prevent them-were in a better position than those who did not have power to manage their 
environment. However, social interruptions are critical for the successful flow of organizational operations because individuals may interrupt their coworkers to solicit advice, gather essential information for their own work responsibilities, or execute an essential plan or task that would be impossible to do without otherwise engaging the needed individual (Jett \& George, 2003). Following from this, great care must be taken not to extend too much leverage to workers for managing their environment, as doing so may impair the functioning of the organizational unit and neglect the urgent needs of coworkers (McFarlane, 1999).

Yet, without some intervention from organizational leaders, it is doubtful that the frequency of social interruptions, as well as their detrimental effects, will wane in the modern workplace. Research has shown that social interruptions provide asymmetrical benefits to workers: Those who do the interrupting often benefit from knowledge gained, while suffering minimal side effects. Those who are interrupted often gain relatively little, while suffering the most (Kraut \& Attewell, 1997). The interrupted are forced to grapple with various impediments, including breaks in concentration that lead to increased error rates (Cellier \& Eyrolle, 1992), impaired memory (Oulasvirta \& Saariluoma, 2004), and increased stress (Kirmeyer, 1988).

Previous research on interruptions has focused on those who do the interrupting, with results indicating that the occurrence of social interruptions tends not to subside when control is left in the hands of potential interrupters (Fogarty et al., 2004). Therefore, we believe that it is best for some power of environmental management to be left in the hands of any employee who is susceptible to being interrupted. With the knowledge of the vital role of social interruptions at hand, practical ideas are necessary to avoid depleting the benefits of interruptions, while awarding workers with a stronger sense of perceived authority over their environment.

There are certain points during the performance of a task when interruptions may be more distracting (Monk, Boehm-Davis, \& Trafton, 2002). If workers are permitted an extra degree of control over interruptions during critical periods of tasks, they may perform better and experience reduced stress. Combining this knowledge with the results of this study, one suggestion for an effective and practical interruption-management procedure is to allow workers some control over the timing of interruptions, while not giving them the ability to prevent them entirely.

Organizations may also offer individuals discretion as to when they can use a daily quota of uninterrupted work time allocated to them by management. This method may maintain the rewards of interruption-free time for workers, while preventing the organization from taking drastic steps that are more likely to impair the fluidity of the work environment, such as entirely banning social interruptions for certain periods of time. However, cues that 
employees lend to signal their desire to not be interrupted will be effective only if they are obeyed. Following from this evidence, care must be taken to identify the employees who will be most adversely affected by social interruptions. Thus, incentives to obey employees' signals for uninterrupted work periods should be provided by management.

A simple signal (e.g., a closed office door) is an effective communications device and interruptions mediator (Nichols, Wobbrock, Gergle, \& Forlizzi, 2002). If workers are provided with assigned periods of time during which they close their doors, pull banners or curtains across their cubicles, or place "Do Not Disturb" signs on their office doors - periods in which they are promised the full ability to avoid the stress and disruptive effects of interruptions - job attitudes and performance may be strongly enhanced.

Individuals who had the ability to control interruptions with a "Do Not Disturb" sign experienced reduced stress, even though none of the participants used this option. This should be very reassuring evidence for leaders. Managers may be able to reduce the stress of their employees by giving them a legitimate opportunity to control interruptions, even if they encourage their workers not to use this option. In a "best-of-both-worlds" scenario, managers can oversee less stressed workers, while not conceding the interactive, interruption-laden office environment that is critical for organizational flow.

Another suggestion for the management of interruptions is to schedule them so that they bundle into a condensed period of time (Kaye, 1999). Bundling may be a creative way to implement the advantages of anticipation that were demonstrated in this study. Workers can be prepared to allocate a preset period of time and mental energy to deal with social interruptions, minimizing resumption lag and other performance-related costs of unanticipated interruptions.

Another important issue for managers relates to role conflict and role ambiguity, which have both been linked to negative outcomes, including anxiety (Kahn, Wolfe, Quinn, Snoek, \& Rosenthal, 1964; Rizzo, House, \& Lirtzman, 1970). A form of role conflict that is particularly relevant is personrole conflict, which occurs when an individual's view of his or her role expectations is discrepant with others' perceptions of the individual's role expectations.

Workers experience role conflict and role ambiguity differentially, based on their position within the organization (Miles, 1977). Internal workers (i.e., those who do not hold positions spanning organizational boundaries) tend to have coworkers and supervisors with consistent expectations of their roles. These workers may experience excessive stress resulting from the interaction of role conflict and interruptions if they are interrupted by coworkers from other organizational units. They also may experience excessive stress from 
the interaction between role ambiguity and interruptions if they are interrupted by several authority figures. Workers who have boundary-spanning roles are likely to be less impacted by interruptions from distant agents and multiple authority figures (Miles, 1977).

\section{Limitations and Directions for Future Research}

Conditions in this study in which participants could prevent interruptions did not allow individuals to control all aspects of the interruptions, including timing and length. Future research should concentrate on expanding the control that individuals have over social interruptions. Future researchers should also consider variations in task complexity. Interruptions may inhibit performance of more complex tasks (Speier, Valacich, \& Vessey, 1999), while enhancing performance of simple tasks. There are several social facilitation theories that account for this possibility (Aiello \& Douthitt, 2001; Guerin, 1993). Distraction-conflict theory (Baron, 1986), for example, holds that distraction may help narrow and focus attention, facilitating simple task performance, yet inhibiting complex task performance.

Interruptions may also have varying effects, based on the goal difficulty of the task (Locke \& Latham, 1990), as well as the interrupter's status (e.g., an authority vs. a subordinate) and position within the organization (Miles, 1977). Additional research should also study more representative samples of organizational members and offer a longitudinal approach to how long-term performance is impacted by social interruptions. Finally, future researchers should investigate the actual effectiveness of different forms of coping mechanisms, including banners, signs, and norms of "interruption-free time" that may be implemented by employees who seek a respite from a frequently interrupted workday.

\section{Conclusions}

The findings from this research suggest that the negative consequences of social interruptions can be addressed by allowing workers more authority over their environment. We urge scholars in social psychology and organizational behavior to continue to investigate this complex phenomenon. Until more is understood regarding the theoretical determinants, mechanisms, and effects of social interruptions, their necessity in modern business contexts suggests that they will continue to remain a burdensome reality for managers and employees. Our belief is that few topics deserve more attention from researchers with an applied orientation than social interruptions. 


\section{References}

Aiello, J. R., \& Douthitt, E. A. (2001). Social facilitation: From Triplett to electronic performance monitoring. Group Dynamics, 5, 163180.

Aiello, J. R., \& Kolb, K. J. (1995). Electronic performance monitoring and social context: Impact on productivity and stress. Journal of Applied Psychology, 80, 339-353.

Aiello, J. R., \& Svec, C. M. (1993). Computer monitoring of work performance: Social facilitation and electronic presence. Journal of Applied Social Psychology, 23, 537-548.

Altmann, E. M., \& Trafton, J. G. (2004). Task interruption: Resumption lag and the role of cues. Proceedings of the 26th Annual Conference of the Cognitive Science Society, 42-47.

Baltes, B. B., Briggs, T. E., Huff, J. W., Wright, J. A., \& Neuman, G. A. (1999). Flexible and compressed workweek schedules: A meta-analysis of their effects on work-related criteria. Journal of Applied Psychology, 84, 496-513.

Baron, R. S. (1986). Distraction-conflict theory: Progress and problems. Advances in Experimental Social Psychology, 19, 1-39.

Brewer, E., \& McMahon-Landers, J. (2003). The relationship between job stress and job satisfaction among industrial and technical teacher educators. Journal of Career and Technical Education, 20, 37-50.

Catania, A. C. (1968). Contemporary research in operant behavior. Glenview, IL: Scott, Foresman \& Co.

Cellier, J., \& Eyrolle, H. (1992). Interface between switched tasks. Ergonomics, 35, 25-36.

Dabbish, L., \& Kraut, R. E. (2004). Controlling interruptions: Awareness displays and social motivation for coordination. Proceedings of the 2004 ACM Conference on Computer-Supported Cooperative Network, 182191.

Fogarty, J., Lai, J., \& Christensen, J. (2004). Presence versus availability: The design and evaluation of a context-aware communication client. International Journal of Human-Computer Studies, 61, 299-317.

Gillie, T., \& Broadbent, D. E. (1989). What make interruptions disruptive? A study of length, similarity, and complexity. Psychological Research, 50, 243-250.

Glass, D. C., \& Singer, J. (1972). Urban stressors: Experiments on noise and social stressors. New York: Academic Press.

Grove, A. S. (1983). High output management. New York: Random House.

Guerin, B. (1993). Social facilitation. Cambridge, UK: Cambridge University Press. 
Hodgetts, H. M., \& Jones, D. M. (2006). Contextual cues aid recovery from interruption: The role of associative activation. Journal of Experimental Psychology: Learning, Memory, and Cognition, 32, 1120-1132.

Jacobs, C. (2004, December). Manage time effectively by putting an end to interruptions. Northern Ontario Business. Retrieved January 5, 2006, from www.northernontariobusiness.com/industry/technology/317301204-managetime

Jett, Q., \& George, J. (2003). Work interrupted: A closer look at the role of interruptions in organizational life. Academy of Management Review, $28,494-507$.

Kahn, R. L., Wolfe, D. M., Quinn, R. P., Snoek, J. D., \& Rosenthal, R. A. (1964). Organizational stress: Studies in role conflict and ambiguity. New York: Wiley.

Karasek, R. A. (1979). Job demands, job decision latitude, and mental strain: Implications for job redesign. Administrative Science Quarterly, 24, 285308.

Kaye, S. (1999). How to handle interruptions that steal your time. Canadian Manager, 24(2), 25-26.

Kirmeyer, S. L. (1988). Coping with competing demands: Interruptions and the Type A pattern. Journal of Applied Psychology, 73, 621-629.

Kraut, R. E., \& Attewell, P. (1997). Media use in a global corporation: Electronic mail and organizational knowledge. In S. B. Keisler (Ed.), Culture in the Internet (pp. 323-342). Mahwah, NJ: Lawrence Erlbaum.

Langer, E. (1983). The psychology of control. Beverly Hills: CA: Sage.

Latorella, K. A. (1999). Investigating interruptions: Implications for flightdeck performance (NASA/TM-1999-209707). Washington, DC: National Aviation and Space Administration.

Locke, E. A., \& Latham, G. P. (1990). A theory of goal-setting and task performance. Englewood Cliffs, NJ: Prentice-Hall.

McCorry, K. J. (2001, August 10-23). Little disruptions can steal away a whole day. Boulder County Business Report. Retrieved January 6, 2006, from www.cubedoor.com/docs/mcCorry_stealwholeday.pdf

McFarlane, D. C., \& Latorella, K. A. (2002). The scope and importance of human interruption in human-computer interaction design. HumanComputer Interaction, 17, 1-61.

McFarlane, D. C. (1999). Coordinating the interruption of people in humancomputer interaction. In A. Sasse \& C. Johnson (Eds.), Proceedings of human-computer interaction (pp. 295-303). Amsterdam, The Netherlands: IOS Press.

Miles, R. H. (1977). Role-set configuration as a predictor of role conflict and ambiguity in complex organizations. Sociometry, 40, 21-34. 
Monk C. A. (2004). The effect of frequent versus infrequent interruptions on primary task resumption. Proceedings of 48th Annual Meeting of the Human Factors and Ergonomics Society, 295-299.

Monk, C. A., Boehm-Davis, D. A., \& Trafton, J. G. (2002). The attentional costs of interrupting task performance at various stages. Proceedings of 46th Annual Meeting of the Human Factors and Ergonomics Society, 1824 1828).

Moray, N. (1993). Formalisms for cognitive modeling. Advances in Human Factor/Ergonomics, 19, 120-125.

Nagata, S., \& van Oostendorp, H. (2003). Multitasking in a mobile context. In P. Gray, H. Johnson, \& E. O'Neill (Eds.), People and Computers, XVII: Designing for society. Proceedings of HCI 2003, (Vol. 2, pp. 145-146). Bath, UK: Research Press International.

Nichols, J., Wobbrock, J. O., Gergle, D., \& Forlizzi, J. (2002). Mediator and medium: Doors as interruption gateways and aesthetic displays. Proceedings of the 4th Annual Conference on Designing Interactive Systems: Processes, Practices, Methods, and Techniques, 379-386.

Oulasvirta, A., \& Saariluoma, P. (2004). Long-term working memory and interrupting messages in human-computer interaction. Behaviour and Information Technology, 23, 53-64.

Perlow, L. A. (1999). The time famine: Toward a sociology of work time. Administrative Science Quarterly, 44, 57-81.

Rizzo, J. R., House, R. J., \& Lirtzman, S. I. (1970). Role conflict and ambiguity in complex organizations. Administrative Science Quarterly, $15,150-163$.

Spector, P. E. (1986). Perceived control by employees: A meta-analysis of studies concerning autonomy and participation. Human Relations, 39, $1005-1016$.

Speier, C., Valacich J. S., \& Vessey, I. (1999). The influence of task interruption on individual decision making: An information overload perspective. Decision Sciences, 30, 337-360.

Yamamotová, A., Starec, M., Holecek, V., Racek, J., Trefil, L., Rasková, H., et al. (2000). Anticipation of acute stress in isoprenaline-sensitive and resistant rats: Strain and gender differences. Basic and Clinical Pharmacology and Toxicology, 87, 161-168. 


\section{Appendix}

\section{Stress Scale}

1. The overall environment made me feel: $1=\operatorname{calm}$ to $7=$ uptight

2. The entire session that I was involved in made me feel: $1=$ not stressed to $7=$ stressed

3. Overall, the session I was involved in and the environment made me feel: $1=$ calm to $7=$ uptight

4. Overall, the session I was involved in and the environment made me feel: $1=$ not distressed to $7=$ distressed

5. Overall, this session was: $1=$ not frustrating to $7=$ frustrating

Note. The scale was adapted from Aiello and Kolb (1995). 